\title{
Work-Related Factors Associated with Low Back Pain Among Nurse Professionals in East and West Wollega Zones, Western Ethiopia, 2017: A Cross-Sectional Study
}

Tesfaye Hambisa Mekonnen

Received: May 1, 2019 / Published online: June 28, 2019

(C) The Author(s) 2019

\section{ABSTRACT}

Introduction: Low back pain (LBP) is yet the persistent public health challenges around the globe. It substantially affects quality of life and poses disability, particularly to the global working population. The profound losses in productivity and compensation premiums due to the condition have also been a challenge to contemporary occupational health. As such, it no doubt demands informed management and due response. The objective of this research was therefore to investigate the prevalence and work-related factors associated with low back pain among nurses in public hospitals in western Ethiopia.

Methods: A health facility-based cross-sectional study was conducted from March to April 2017. A sample of 422 nurses was selected using systematic random sampling technique. The standardized Nordic Musculoskeletal survey was

Enhanced Digital Features To view enhanced digital features for this article go to: https://doi.org/10.6084/ m9.figshare.8242583.

T. H. Mekonnen ( $\varangle)$

Department of Environmental and Occupational Health and Safety, Institute of Public Health, College of Medicine and Health Sciences, University of Gondar, Gondar, Ethiopia e-mail: tajan2022@gmail.com interviewer-administered for data collection. The association of different explanatory variables with LBP was explored using a binary logistic regression analysis. The significance of associations was ascertained at a $p$ value of $<0.05$ and odds ratios (OR) with 95\% confidence intervals $(\mathrm{CI})$.

Results: The response rate was 99\% $(N=418)$. The mean age was 31.39 (standard deviation \pm 7.01 ) years. The prevalence of LBP in the past 12 months was $63.6 \%(N=266)$ [95\% CI $(58.9,68.2)]$. About $34.2 \%(n=91)$ of the victims had sought medical care. The prevalence in the last 7 days was $53.4 \% \quad(n=142)$. The majority, $72.2 \%(n=192)$, indicated that their activity was limited. Work experience [AOR 4.332; 95\% CI $(2.550,7.360)]$, shift work [AOR $2.118 ; 95 \%$ CI $(1.165,3.850)]$, and health and safety training [AOR 2.058; 95\% CI (1.127, 3.063)] were significantly associated with low back pain.

Conclusions: The prevalence of low back pain was high, as in many other studies. The finding implies that practices and implementations that focus on the prevention and control of back pain injuries should target proper management of workplace conditions, like shift work and provision of health and safety training.

Keywords: Ethiopia; Low back pain; Nurses; Work-related factors 


\section{INTRODUCTION}

Low back pain (LBP) is a persistent public health issue of people around the globe. The health burden relating to the quality of life, disability, and economic impacts due to healthcare costs necessitate continuous public health response [1-3]. Previous investigation has explored that low back pain is the cause for an estimate of 83 million disability-adjusted life years (DALYs) in 2010 [4]. Low back pain is the most common type of musculoskeletal disorder usually related to work and working conditions $[5,6]$. It is one of the contemporary occupational health ailments that seizes attention due to the substantial lost productive time and employee absenteeism it often incurs $[7,8]$. For example, according to the Health and Safety Executive (HSE), about 1.8 million working days were lost in 2016/17 because of back pain disorders [6].

Nursing is an occupation most often susceptible to the risks of low back pain $[6,9,10]$. The inherent nature of activities in nursing, such as twisting, bending, sustained posture, and repeated movements create favorable conditions for LBP $[8,9]$. Hence, a number of studies conducted on nurses worldwide showed that the prevalence of LBP was usually apparent. For instance, a study in Nepal exhibited the prevalence of $75.7 \%$ [11], South Africa 59\% [12], Nigeria 33.3\% [10] and 73.53\%) [13], Tunisia $58.1 \%$ [14], Uganda 58.7\% [15], Malaysia 68.2\% [16], Iran 54.3\% [17], and Ethiopia 41.4\% [8]. Generally, literature has indicated that the prevalence of low back pain ranges from 40 to $97.9 \%[3]$.

The experience of low back pain related to the inherent nature of the nursing profession is usually determined by several driving factors. For example, recent studies demonstrate workrelated LBP is often influenced by socio-demographic attributes, like sex, age, marital status, body mass index, experience $[9,10,15,16$, 18, 19]. Moreover, life-style factors, including smoking, obesity, and lack of physical activity and psychological factors, such as stress and job satisfaction $[1,19]$ have been examined to considerably affect the developments of low back pain. Studies also reveal that workplace conditions, such as overtime work, long working hours, working posture, and shift work $[9,10,16,17,19,20]$ are important predictors of low back pain.

Intensive research has been conducted on back pain prevalence and its associated factors that trigger its development among nurse professionals globally. However, evidence that can assist in devising policies for prevention and control of low back pain among nurses in Ethiopia is negligible. Therefore, the objective of this study was to explore the prevalence and work-related factors affecting LBP among nurses in east and west Wollega zones, Ethiopia.

\section{METHODS}

This was a cross-sectional study conducted from March to April 2017 in east and west Wollega zones public hospitals, western Ethiopia. The two neighboring zones are located about 320 and $495 \mathrm{~km}$ from Addis Ababa, the capital of Ethiopia, respectively. The four public hospitals in the two zones employ more than 990 healthcare providers. All the hospitals were purposively included in the study to attain the required sample size.

\section{Populations and Sample Size}

All nurses working in east and west Wollega zones public hospitals were the source population. Nurses who had worked for at least 12 months prior to the inception of the study were randomly selected, excluding those who were on sick, annual, maternity, and other leaves. Thus, 422 nurses were selected using single population proportion formula, with a $50 \%$ proportion of low back pain, $5 \%$ margin of error, and $10 \%$ assumption for no responses.

\section{Data Collection Tools and Procedures}

Systematic random sampling technique was employed to recruit participants. Data were collected using a face-to-face interviewer-administered questionnaire. The standardized Nordic Musculoskeletal questionnaire was used 
to assess prevalence of low back pain [21]. Perceived severity and disability of LBP were evaluated according to the Von Korff pain severity grading [22]. The generic job satisfaction scale questionnaire was used to evaluate job satisfaction [23], and workplace stress scale questionnaire to score perceived job stress [24]. Detailed information regarding socio-demographic characteristics, like sex, age, religion, educational level, marital status, monthly salary, and work experience were incorporated. Different occupational attributes, like working hours per day, department, pre and periodic medical examinations, shift work, health and safety training, and overtime were collected. Parts of the questionnaire also included health and psychosocial factors, like perceived severity and disability of LBP, job satisfaction, and job stress. Lastly, life-style factors that constitute physical exercise (yes/no), smoking (yes/no), and body mass index (BMI) (weight divided by height square) were also gathered.

\section{Data Quality Control}

The data collection tool was first designed in English and translated into the local language, 'Afaan Oromo', and back to English by language experts. Second, training and orientation was provided for data collectors and supervisors for 2 days on issues relating to the objectives of the study, confidentiality of information, inclusion and exclusion criteria, and about informed consent of participants. Finally, a pilot test was conducted on $5 \%$ of the sample (19 participants) at a neighboring hospital (Arjo district hospital) to ensure the reliability and consistency of the instrument). Based on the pretest analysis, unclear questions modified and the number of questions reduced without missing what has been intended to be assessed.

\section{Data Analysis}

Data were cleaned, coded, and entered into EPI info version 7 and exported to SPSS version 20 for analysis. Descriptive statistics were used to present the findings. The reliability of the questionnaire was tested using Cronbach's alpha
$($ Cronbach's alpha $=0.775)$. The associations between LBP and the independent variables were investigated using the binary logistic regression analysis. Independent parameters with $<0.2$ $p$ value in the bivariate analysis were exported to the multivariable logistic regression model to control the effects of potential confounders. Goodness of fit for the model was checked using Hosmer and Lemeshow ( $p$ value $>0.05$ ). The significance of associations was established at a $\leq 0.05 p$ value with $95 \% \mathrm{CI}$ and odds ratios (ORs).

\section{Operational Definitions}

Body mass index (BMI) $<18.5=$ underweight; 18.5-24.99.0 = normal; $\geq 25.0=$ over weight $/$ obesity.

Perceived disability $=$ A pain disability point score of 3-6 points [22].

Perceived severity (intensity) $=\mathrm{A}$ pain intensity score of $\geq 50$ or $<3$ disability points [22].

Stressed worker: The workplace stress scale score of 21 or above [25].

Job satisfied worker: The generic job satisfaction scale score of 32 or above [23].

\section{Compliance with Ethics Guidelines}

The Institutional Ethical Review Board of the University of Gondar issued on ethical clearance letter (Reference \#: EOHS/543/2008). The letter was submitted to the managers of each public hospital selected. Consent from each participant was then secured. Participation was voluntary and withdrawal from the study was highly respected. To ensure and maintain confidentiality, only aggregate data were used for interpretations. Therefore, the study agreed with the Helsinki Declaration of 1964 and its related amendments in this regard.

\section{RESULTS}

\section{Socio-Demographic Characteristics}

A total of 418 nurses fully answered the interview questions with $99 \%$ response rate. The 
majority of the nurses, $55.7 \%(N=233)$, were females. Age ranged from 21 to 69 with a mean of 31.39 ( $\mathrm{SD} \pm 7.01$ ) years. More than half, $63.9 \%(N=267)$, of the participants' age group fell between 25 and 35 years. A high proportion of the respondents were of the Oromo ethnic group, $77.8 \%(N=325)$. Regarding marital status, $54.5 \%(N=228)$ of nurses said they had got married. Of the respondents, $48.6 \%(N=203)$ were Bachelor of Science degree (BSc) graduates in educational status (Table 1 ).

\section{Behavioral and Psychosocial Characteristics of the Participants}

Among the respondents, $33.3 \% \quad(N=149)$ reported that they were alcohol users. Eightyseven percent $(N=367)$ of the participants said they were never smokers, $2.2 \%(N=9)$ were passive smokers, and $10.0 \%(N=42)$ were current smokers. Regarding physical exercises, $28.5 \%(N=119)$ elucidated that they perform physical exercise. Concerning the frequencies of physical exercise, $7.0 \%(N=29)$ of the participants showed they execute exercise for $1-2 \mathrm{~h}$ per day, $4.8 \%(N=20)$ for $>2 \mathrm{~h}$ per day, $12.7 \%$ $(N=53) 1-3$ times per week, and $4.1 \%(N=17)$ ever day. Regarding job satisfaction, $54.1 \%$ $(N=226)$ explained they were satisfied with their jobs, while the remaining nurses clarified they were not. Less than half, $47.6 \%(N=199)$, of the respondents represented they were stressed due to their current jobs. With reference to body mass index, $96.2 \%(N=402)$ of the nurses indicated their body mass index was normal while $3.8 \%(N=16)$ of them reported to be overweight.

\section{Prevalence and Characteristics of Low Back Pain}

The prevalence of low back pain 12 months before the start of the study was $63.6 \%$ $(N=266)$; $[95 \%$ CI of $(58.9,68.2)]$ and $53.4 \%$ $(n=142)$ in the last 7 days. Of the total cases, only $34.2 \%(n=91)$ [95\% CI of $(28.2,39.9)$ ] sought medical services. The majority, $72.2 \%$ $(n=192)$, also said that their activity was limited due to their low back disorders. A high
Table 1 Socio-demographic characteristics of study participants, western Ethiopia, 2017

\begin{tabular}{|c|c|c|}
\hline Variables $(N=418)$ & Frequency & $\%$ \\
\hline \multicolumn{3}{|l|}{ Sex } \\
\hline Male & 185 & 44.3 \\
\hline Female & 233 & 54.7 \\
\hline \multicolumn{3}{|l|}{ Age } \\
\hline$\leq 24$ & 73 & 17.5 \\
\hline $25-35$ & 267 & 63.9 \\
\hline$>35$ & 78 & 18.7 \\
\hline \multicolumn{3}{|l|}{ Religion } \\
\hline Orthodox & 150 & 35.9 \\
\hline Muslim & 97 & 23.2 \\
\hline Protestant & 142 & 34.1 \\
\hline Others* & 29 & 6.9 \\
\hline \multicolumn{3}{|l|}{ Marital status } \\
\hline Single & 156 & 37.3 \\
\hline Married & 228 & 54.5 \\
\hline Separated/divorced/widowed & 34 & 8.1 \\
\hline \multicolumn{3}{|l|}{ Educational level } \\
\hline Diploma & 217 & 51.9 \\
\hline First degree $(\mathrm{BSc})$ & 139 & 33.3 \\
\hline Masters degree & 62 & 14.8 \\
\hline \multicolumn{3}{|l|}{ Monthly salary in ETB } \\
\hline$\leq 3500$ & 145 & 34.7 \\
\hline $3501-4500$ & 72 & 17.2 \\
\hline$>4500$ & 201 & 48.1 \\
\hline \multicolumn{3}{|l|}{ Ethnicity } \\
\hline Oromo & 301 & 72 \\
\hline Amhara & 67 & 16 \\
\hline Tigre & 37 & 8.9 \\
\hline Gurge & 13 & 3.1 \\
\hline
\end{tabular}

${ }^{*}$ Wakefata Catholic and Adventists, $B S c$ Bachelor of Science degree, ETB Ethiopian Birr (currency), $N$ number 
Table 2 Factors affecting low back pain among nurses, western Ethiopia, 2017

\begin{tabular}{|c|c|c|c|c|c|}
\hline \multirow[t]{2}{*}{ Variables $(N=270)$} & \multicolumn{2}{|c|}{ Low back pain } & \multirow[t]{2}{*}{ COR $(95 \% \mathrm{CI})$} & \multirow[t]{2}{*}{$\operatorname{AOR}(95 \% \mathrm{CI})$} & \multirow[t]{2}{*}{$p$ value } \\
\hline & Yes & No & & & \\
\hline \multicolumn{6}{|l|}{ Marital status } \\
\hline Single & 75 & 81 & $0.331(0.215,0.509)$ & $0.618(0.336,1.135)$ & $<0.102^{+}$ \\
\hline Married & 168 & 60 & $0.443(0.202,0.970)$ & $0.526(0.189,1.460)$ & $<0.211^{+}$ \\
\hline Separated/divorced/widowed & 23 & 11 & 1 & 1 & \\
\hline \multicolumn{6}{|l|}{ Monthly salary } \\
\hline$\leq 3500$ & 94 & 51 & $1.110(0.70,1.741)$ & $0.835(0.417-1.673)$ & $<0.130^{+}$ \\
\hline $3501-4500$ & 37 & 35 & $1.935(1.119,3.347)$ & $0.950(0.463-1.950)$ & $<0.061^{+}$ \\
\hline$>4500$ & 135 & 66 & 1 & 1 & \\
\hline
\end{tabular}

Educational level

Diploma

First degree (BSc)

Masters degree

Job stress

Not stressed $(<21$ score $)$

Stressed ( $\geq 21$ score)

Work experience

$<5$ years

$\geq 5$ years

126

91

$97 \quad 42$

43

19

147

119

120

146

125

27

106

160

94

58

63

203

48

104

151

75

115

77

39

227

50

102

1

Yes

Safety training

No

1

52

1

Shift work

No
$1.635(0.894,2.989)$

$0.980(0.512,1.877)$

$0.508(0.210,1.228)<0.102^{+}$

$0.917(0.387,2.173)$

1

$<0.060^{+}$

$2.376(1.572,3.591)$

1

$1.374(0.813,2.322) \quad<0.068^{+}$

$5.633(3.482,9.112)$

$4.332(2.550,7.360)<0.0001^{*}$

1

1

$0.21(0.13,4.12)$

$<0.061^{+}$

$0.409(0.272,0.615)$

1

$0.672(0.431,1.048)$

1

$<0.080^{+}$

$0.456(0.016,2.026)$

1

$1.349(0.904,2.611) \quad 1.067(0.614,1.855)<0.103^{+}$

$3.040(1.984,4.698)$

$2.058(1.127,3.063)$

$<0.001^{*}$ 
Table 2 continued

\begin{tabular}{llllll}
\hline Variables $(N=270)$ & \multicolumn{2}{l}{ Low back pain } & COR (95\% CI) & AOR (95\% CI) & $p$ value \\
\cline { 2 - 3 } & Yes & No & & 1 \\
\hline Yes & 62 & 73 & 1 & 1 \\
\hline
\end{tabular}

$A O R$ adjusted odds ratios, $B S c$ bachelor of science, $C I$ confidence interval, $C O R$ crude odds ratios, $L B P$ low back pain

+ Significant in a bivariate analysis

* Significant in a multivariable analysis

proportion, $54.1 \%(n=144)$, of the reported back complaints were observed in females. The majority, $61.7 \%(n=164)$, of the participants with back pain conditions fall in the middle age (25-35 years). Sixty-three percent $(n=168)$ of the respondents with LBP were married and $28.2 \%(n=75)$ single. Around half, $47.7 \%$ $(n=127)$, of the LBP sufferers stated that they perceived high disability, while $35.3 \%(n=94)$ indicated their pain was intense (severe). About $56.8 \%(n=151)$ of the interviewees with LBP remarked that they were satisfied with their jobs, whereas $44.7 \%(n=119)$ pointed out that they were stressed with their jobs. The majority, $60.2 \%(n=160)$, of the interviewees with LBP reported that they worked $>8 \mathrm{~h}$ per day. About $85.3 \%(n=227)$ exhibited they worked in shifts, whereas $76.7 \% \quad(n=204)$ demonstrated that they did not take any workplace health and safety training. More than half, 54.9\% ( $n=146)$, had work experience of $\geq 5$ years and the remaining $<5$ years of service at their workplaces.

\section{Factors Associated with Low Back Pain}

The results of bivariate analysis revealed that independent variables including marital status, educational level, monthly salary, work experience, overtime work, working hours, job stress, job satisfaction, and health and safety training were associated factors of low back pain.

According to the multivariable regression analysis, work experience, shift work, and health and safety training were significant factors associated with low back pain. The odds of developing LBP were 4.332 times more likely among those whose work experience was $<5$ years than workers with $\geq 5$ years of work experience [AOR 4.332; 95\% CI (2.550, 7.360)]. The participants who worked shift work were 2.118 times more likely to experience LBP than workers who did not [AOR 2.118; 95\% CI $(1.165,3.850)]$. The likelihood of developing low back pain doubled among nurses who did not get any occupational health and safety training compared to those who received the training [AOR 2.058; 95\% CI $(1.127,3.063)$ ] (Table 2).

\section{DISCUSSION}

This study was a facility-based cross-sectional study conducted to investigate the prevalence of and factors influencing low back pain among nurses working in east and west Wollega zones public hospitals, Ethiopia. The findings of the study revealed that the prevalence of LBP in the previous 12 months was $63.6 \%(N=266)$ [95\% CI $(58.9,68.2)]$. The high prevalence observed in the current study could imply that workplace safety practices and hazard prevention and control strategies are poorly implemented in the country, particularly in the study setting.

This result was relatively comparable with those of studies in Malaysia (68.2\%) [16] and South Africa (59\%) [12]. This could be due to that the inherent nature of working conditions and practices of nursing is often almost similar in every country, regardless of economic status. This study found a higher prevalence of LBP compared to that of the finding in Ethiopia (Adama Hospital) 41.4\% [8], Nigeria 33.3\% [10], Tunisia 58.1\% [14], India 53.4\% [9], and Iran $54.3 \%$ [23]. Our finding was, however, lower than the 90\% report in Finland [26], 77.1\% Turkey [27], 75.7\% Nepal [11], 73.53\% Nigeria 
[13], 70.8\% Bahrain [7], and 87.5\% in Sudan [5]. This disparity could be due to differences in workplace illnesses and injury prevention and reporting procedures, variations in study methodologies, and differences in defining cases and perceiving disability and the severity of LBP across countries.

In this study, it has been observed that the length of employment (work experience) was an important predictor of low back pain among nurse professionals. This result was different from those of several investigations $[9,15,18,19,28,29]$. The studies found that workers with relatively longer employment duration (with some reference time frame) were more likely to be vulnerable to back pain complaints compared to workers with lower work experience. In this study, however, workers with $<5$ years of service found more likely to have had experience back pain conditions than those with $\geq 5$ years of work experience. Workers with comparatively lower length of employment might usually lack awareness and skills towards safety procedures and hazard control mechanisms and are, therefore, often prone to occupational injuries and accidents.

Shift work is the other working condition evaluated to considerably predict the occurrence of low back pain among nurses. Participants who engage in a day/night work rotation approach are likely to manifest LBP than the ones who engage only in day time. This finding was in agreement with those of the recent studies [17, 23, 30-33]. The normal circadian cycle of human beings might be disturbed due to day and night rotation systems of working arrangements. Such disturbances of the biological rhythm of humans might enhance favorable conditions for injuries and diseases to take place.

Multivariable logistic regression analysis also elucidated that the absence of health and safety training increases vulnerability to LBP conditions. The proximal association between safety training and LBP has rarely been studied. Workers' health and safety awareness and training, however, could play a greater role in hazard and risk prevention and control measures. Safety training more likely promotes workplace cultures of safety practices. Training might also result in behavioral changes of employees targeted to healthy life-styles, such as physical exercise, which could in turn lead to a reduced probability of back pain complaints.

In the current study, few limitations have not been ruled out. A simultaneous assessment of the cause-and-effect relationship is the usual limitation of a cross-sectional design. Therefore, the plausibility of the findings might be uncertain for generalizability. Recall bias and the under-estimation of self-reported data could also be apparent. Moreover, focusing on specific working segments alone might not be a representative of the other workforces and industry sectors. Therefore, it is quite advisable to address ranges of industry sectors with stronger study designs, longitudinal, for example, to investigate similar issues.

\section{CONCLUSIONS}

The prevalence of LBP was high, as in many other studies. The length of employment, work shift, and lack of health and safety trainings considerably affected LBP conditions. The finding implies that the practices and implementations that focus on the prevention and control of back pain injuries should target the proper management of workplace conditions, like shift work and regular provision of health and safety trainings.

\section{ACKNOWLEDGEMENTS}

The author would like to cordially extend acknowledgments to the University of Gondar, for provision of ethical clearance and Oromia Labour and Social Affairs Bureau for their heartfelt cooperation and support letter provisions. The author also thanks the participants of the study and data collectors.

Funding. No funding or sponsorship was received for this study or publication of this article.

Authorship. All named authors meet the International Committee of Medical Journal 
Editors (ICMJE) criteria for authorship for this article, take responsibility for the integrity of the work as a whole, and have given their approval for this version to be published.

Disclosures. Tesfaye Hambisa Mekonnen has nothing to disclose.

Compliance with Ethics Guidelines. The Institutional Ethical Review Board of the University of Gondar issued on ethical clearance letter (Reference \#: EOHS/543/2008). The letter was submitted to the managers of each public hospital selected. Consent from each participant was then secured. Participation was voluntary and withdrawal from the study was highly respected. To ensure and maintain confidentiality, only aggregate data were used for interpretations. Therefore, the study agreed with the Helsinki Declaration of 1964 and its related amendments in this regard.

Data Availability. The dataset generated and analyzed during the current study is available from the corresponding author on reasonable request.

Open Access. This article is distributed under the terms of the Creative Commons Attribution-NonCommercial 4.0 International License (http://creativecommons.org/licenses/ by-nc/4.0/), which permits any noncommercial use, distribution, and reproduction in any medium, provided you give appropriate credit to the original author(s) and the source, provide a link to the Creative Commons license, and indicate if changes were made.

\section{REFERENCES}

1. Clark S, Horton R. Low back pain: a major global challenge. The Lancet 2018. https://nikkb.dk/ images/backpainseries.pdf. Accessed Nov 6, 2018.

2. Yitayeh A, Fasika S, Mekonnen S, Gizachew M. Work-related musculoskeletal disorders and associated factors among nurses working in governmental health institutions of Gondar town, Ethiopia, 2013. Physiotherapy. 2015;101:e1694.
3. Tosunoz IK, Oztunc G. Low back pain in nurses. Int J Caring Sci. 2017;10(3):1728-32.

4. Hoy D, March L, Brooks P, Blyth F, Woolf A, Bain C, et al. The global burden of low back pain: estimates from the Global Burden of Disease 2010 study. Ann Rheum Dis. 2014;73(6):968-74.

5. Al-samawi MAG, Awad HMAA. Prevalence of low back pain among nurses working in Elmak Nimer University hospital-Shendi-Sudan 2015. Int J Res Granthaalayah. 2015;3(9):108-21.

6. Health and Safety Executive. Work-related Musculoskeletal Disorders (WRMSDs) Statistics in Great Britain 2017. 2017. http://www.hse.gov.uk/ statistics/causdis/musculoskeletal/msd.pdf. Accessed Nov 6, 2018.

7. Qareeballa AA, Alhamdan OA, Almutawaa AA, Alsayed IM, Kamal FA, Al Abdrabbuh DS, et al. Prevalence of low back pain among female nurses working in secondary and tertiary healthcare, kingdom of Bahrain. Int J Med Sci Public Health. 2018;7(3):183-8.

8. Alem D, Ephrem M, Seblewengel L. Prevalence of low back pain and associated risk factors among Adama Hospital Medical College Staff, Ethiopia. Eur J Prev Med. 2015;3(6):188-92.

9. Emmanuel NM, Ezhilarasu P, Bheemarao AB. Low back pain among nurses in a tertiary hospital, south India. J Osteoporos Phys Act. 2015;4:1-3.

10. Johnson OE, Emmanuel E. Prevalence and risk factors of low back pain among workers in a health facility in South-South Nigeria. Br J Med Med Res. 2016;11(8):1-8.

11. Manandhar N, Subedi S. Prevalence and risk factors of low back pain among nurses of a medical college at Bharatpur, Nepal. Scirea J Health. 2016;1(1):1-10.

12. Dlungwane T, Voce A, Knight S. Prevalence and factors associated with low back pain among nurses at a regional hospital in KwaZulu-Natal, South Africa. Health SA Gesondheid. 2018;15:85. https:// doi.org/10.4102/hsag.v23i0.1082:1-6.

13. Sikiru L, Hanifa S. Prevalence and risk factors of low back pain among nurses in a typical Nigerian hospital. Afr Health Sci. 2010;10(1):26-30.

14. Boughattas W, El Maalel O, Maoua M, Bougmiza I, Kalboussi H, Brahem A, et al. Low back pain among nurses: prevalence, and occupational risk factors. Occup Dis Environ Med. 2017;5(01):26-37.

15. Mutanda T, Mwaka E, Sekimpi P, Ntuulo J. Occupation-related musculoskeletal disorders among 
nurses at the National Referral Hospital, Mulago in Uganda. Occup Med Health Aff. 2017;5(3):1-5.

16. Gim CS. Factors associated with low back pain among nurses in critical care units, Hospital Universiti Sains Malaysia. Biomed J Sci Tech Res. 2017;1(7):1-6.

17. Ahmadi M, Rezaiee J, Hashemian AH. Prevalence and risk factors of low back pain among nurses in an Iranian Hospital, (Kermanshah, 2012). Adv Biol Res. 2014;8(4):168-70.

18. Thon CC, Feng PKJ, Lian CW. Risk factors of low back pain among nurses working in Sarawak General Hospital. Health Environ J. 2016;7(1):13-24.

19. Şimşek Ş, Yağcı N, Şenol H. Prevalence and risk factors of low back pain among health-care workers in Denizli. Ağrı J Turk Soc Algol. 2017;29(2):71-8.

20. Sanjoy SS, Ahsan GU, Nabi H, Joy ZF, Hossain A. Occupational factors and low back pain: a crosssectional study of Bangladeshi female nurses. BMC Res Notes. 2017;10(173):1-6.

21. Kuorinka I, Jonsson B, Kilbom A, Vinterberg H, Biering-Sørensen F, Andersson G, et al. Standardised Nordic questionnaires for the analysis of musculoskeletal symptoms. Appl Ergon. 1987;18(3): 233-7.

22. Von Korff M, Ormel J, Keefe FJ, Dworkin SFJP. Grading the severity of chronic pain. Pain. 1992;50(2):133-49.

23. Macdonald S, Maclntyre P. The generic job satisfaction scale: scale development and its correlates. Empl Assist Q. 1997;13(2):1-16.

24. Copyright (C) The Marlin Company NH, CT, and the American Institute of Stress, Yonkers, NY. The Workplace Stress Scale ${ }^{\mathrm{TM}}$. https://teorionline.files. wordpress.com/2011/04/unit-3-the-workplace-stre ss-scale.pdf. Accessed Nov 6, 2018.

25. The Marlin Company NH, CT, The American Institute of Stress, Yonkers, NY. The Workplace
Stress Scale ${ }^{\mathrm{TM}}$. https://teorionline.files.wordpress. com/2011/04/unit-3-the-workplace-stress-scale.pdf. Accessed Oct 25, 2018.

26. Theodora K, Dimosthenis Z, Michael K, Athanasios $K$, Evaggelos S. Looking into the factors affecting low back pain incidents in general hospital nurses: a questionnaire research. Sci J Hell Regul Body Nurses. 2010. http://journal-ene.gr/wp-content/ uploads/2010/11/Tomos03_teyxos02eng-dragged1. pdf. Accessed on Nov 6, 2018.

27. Karahan A, Kav S, Abbasoglu A, Dogan N. Low back pain: prevalence and associated risk factors among hospital staff. J Adv Nurs. 2009;65(3):516-24.

28. Yitayeh A, Mekonnen S, Fasika S, Gizachew M. Annual prevalence of self-reported work-related musculoskeletal disorders and associated factors among nurses working at Gondar Town Governmental Health Institutions, northwest Ethiopia. Emerg Med (Los Angel). 2015;5(1):1-8.

29. Tamrin SBM, Yokoyama K, Jalaludin J, Aziz NA, Jemoin N, Nordin R, et al. The association between risk factors and low back pain among commercial vehicle drivers in peninsular Malaysia: a preliminary result. Ind Health. 2007;45(2):268-78.

30. Zhao I, Bogossian F, Turner C. Shift work and workrelated injuries among health care workers: a systematic review. Aust J Adv Nurs. 2010;27(3):62-74.

31. Eriksen W, Bruusgaard D, Knardahl S. Work factors as predictors of intense or disabling low back pain; a prospective study of nurses' aides. Occup Environ Med. 2004;61(5):398-404.

32. Attarchi M, Raeisi S, Namvar M, Golabadi M. Association between shift working and musculoskeletal symptoms among nursing personnel. Iran J Nurs Midwifery Res. 2014;19(3):309-14.

33. Amer S. Work-related musculoskeletal symptoms among nurse staff in Islamia, Egypt. Egypt J Occup Med. 2018;42(1):61-78. 